\title{
ГРАНИЦА СРЕДНЕГО И ВЕРХНЕГО ДЕВОНА В РАЙОНЕ УСТЬЯ Р. АБАВА (ЛАТВИЯ)
}

На территории Западной Латвии, на левом берегу р. Абава напротив хутора Лееи *, в 4 км выше устъя реки находится крупный обрыв, который в течение двадцати лет рассматривался как обнажение границы между средним и верхним девоном, одно из редких в Прибалтике. Это обнажение было детально изучено в связи с нахождением здесь в слое конгломерата (мощностью до 0,5 м) остатков рыб живетского и франского возрастов (Лярская, 1966). Раньше П. П. Лиепиньшем из этого местонахождения были определены Ganosteus stellatus Rohon, Psammolepis abavica Mark-Kurik, Livosteus grandis (Gross), Homostius sp., Asterolepis sp., Osteolepis sp. На этом основании он выделил верхнюю часть салацской свиты в самостоятельную абавскую свиту в составе живетского яруса (Лиепиньш, 1960). Абавская свита, по кровле которой проводилась граница между средним и верхним девонам, оказалась, таким образом, переходной.

Сборы остатков рыб и детальные раскопки на обнажении Лееи проводились в 1958 г. под руководством Д. В. Обручева и в 1964 г. Л. А. Лярской. В результате список рыб дополнился еще несколькими формами - Homacanthus sp., Haplacanthus marginalis Ag., Devononchus concinnus Gross, Plourdosteus(?) panderi O. Obr., Glyptolepis sp. Изучение условий захоронения остатков рыб привело к выводу о переотложении костей живетских рыб и о позднедевонском возрасте слоя конгломерата, содержащего эти остатки. Отмечалась необходимость дальнейшего изучения органических остатков и уточнения возраста нижней части разреза обнажения под слоем конгломерата (Лярская, 1966). В последующих работах по стратиграфии девонских отложений, с учетом данных Л. А. Лярской, граница между средним и верхним девоном проводилась по контакту слоя конгломерата с подстилающей его пачкой переслаивающихся глин, песчаников и алевролитов. Эти породы, в свою очередь, перекрывают обнаженные над урезом воды в реке желтовато-красные песчаники (рис. 1). Критерием проведения границы по подошве конгломерата стал несколько обновленный состав ихтиофауны и, в частности, находки крупных представителей рода Asterolepis, характерных для позднедевонской гауйской свиты.

В 1982 г. студентом Латвийского госуниверситета Ю. М. Битениексом из слоя конгломерата обн. Лееи была найдена хорошо сохранившаяся пластинка еще одной среднедевонской рыбы - Actinolepis sp. B этом же году было проведено литологическое изучение конгломератов и других пород рассматриваемого района. Внутриформационный характер конгломерата и отсутствие в нем принесенных издалека глыб среднедевонских пород (рис. 2) позволили предположить в обн. Лееи существование этапа развития бассейна с переходной средне-позднедевонской ихтиофауной (Куршс, 1986).

\footnotetext{
* На латышском языке Lejēji означает «нижние». На топографических картах и в материалах геологической съемки по причине технической ошибки хутор неправильно назван Лесн.
} 


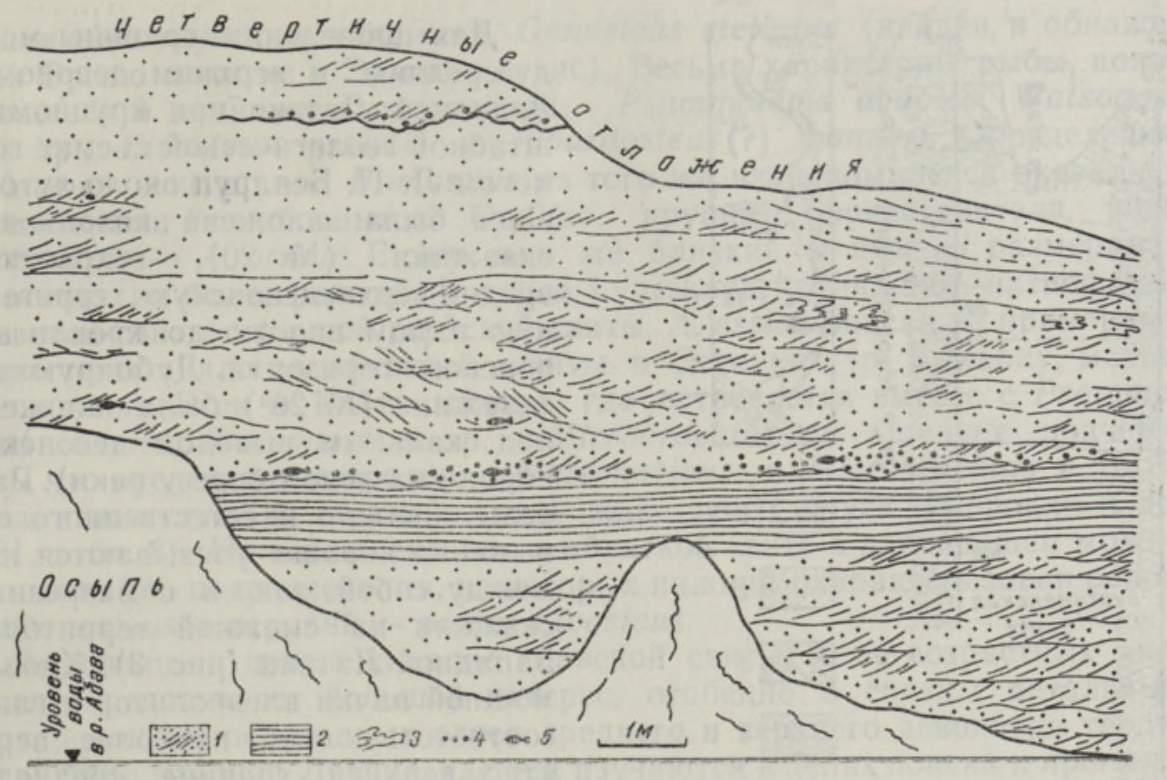

Рис. 1. Зарисовка северо-западной стенки обнажения девонских пород на левом берегу p. Абава напротив хутора Лееи. 1 - песчаники косослоистые; 2 - переслаивание глин, песчаников и алевролитов; 3 - оползневые деформации косой слоистости; 4 - галька глин, алевролитов, кварца и фосфоритов; 5 - скопления остатков рыб. Горизонталь: ның̆ и вертикальный масштабы равные.

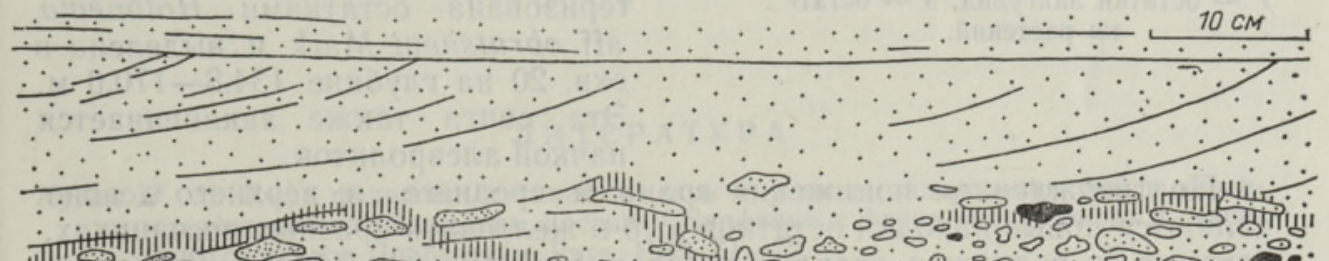

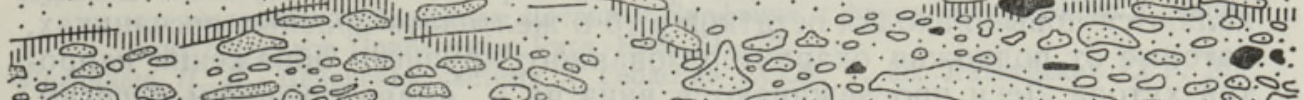

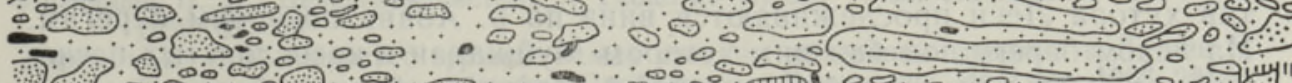

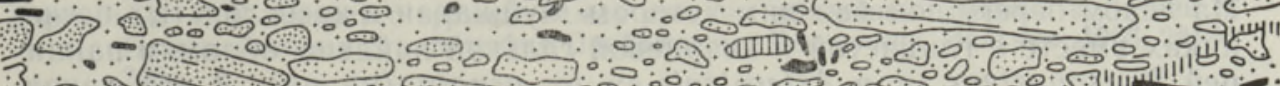
$3 \%$ o\%

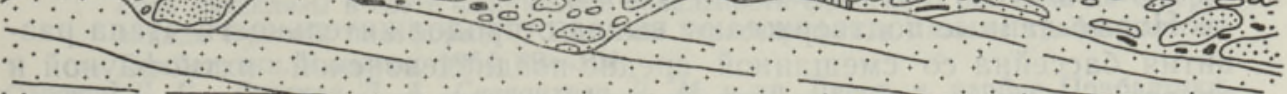

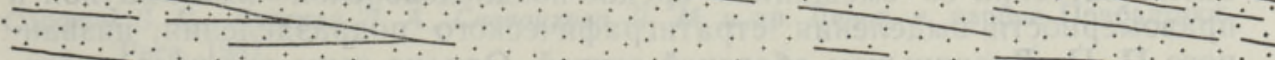
$\because \therefore \quad \therefore \quad \therefore$. $\frac{0}{5} \cdot \frac{0}{2}$ $\because 10$ E 203

Рис. 2. Зарисовка детали стенки обнажения напротив хутора Лееи на уровне слоя конгломерата. 1 - песчаники; 2 - глины; 3 - галька глин и алевролитов; 4 - остатки рыб; 5 - зоны вторичного ожелезнения. Горизонтальный и вертикальный масштабы равные. 


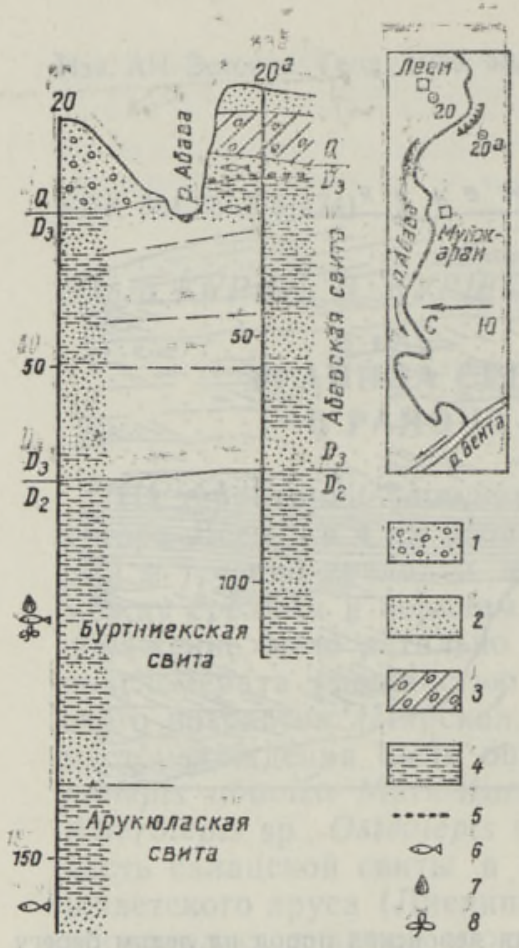

Рис. 3. Сопоставление разреза обкартировочных скважин. 1 - песчано-гравийные аллювиальные отложения; 2 - пески и песчаники; 3 - моренный суглинок; 4 - глины и алевролиты; 5 - галька глин и алевролитов; 6 - остатки рыб; 7 - остатки лингулид; 8 - остатки растений. нажения на р. Абава с разрезами

Для проведения границы между средним и верхним девоном в Западной Латвии при крупномасштабной геологической съемке геологом Л. П. Бендруп около хутора Лееи была заложена колонковая скважина (№ 20), вскрывшая средне-верхнедевонскую терригенную толшу вплоть до кровли наровского горизонта. Дублирующая скважина, (№ 20а) была заложена над скальным выходом девонских пород (на левом берегу реки). Разрезы скважин и естественного обнажения хорошо увязываются как между собой, так и с разрезами скважин на смежной территории Западной Латвии (рис. 3). Кровля мощной пачки алевролитов и глин, соответствующая, наиболее вероятно, верхней границе среднедевонской буртниекской свиты, вскрыта скв. 20 на глубине 74,0 м. В низах этой пачки, на глубине $100 \mathrm{M}$ обнаружены типичные для буртниекской свиты остатки. Tartuosteus maximus Mark-Kurik. Таким образом, границу среднего и верхнего девона можно понизить на 59 м.

Арукюлаская свита, венчающая разрез эйфельского яруса, охарактеризована остатками Holonema aff obrutshevi Mark и выделена в скв. 20 на глубине $134,8-170,0$ м. Эта свита также заканчивается пачкой алевролитов.

Подтверждением понижения границы среднего и верхнего девона являются новые находки остатков рыб в желтовато-красных песчаниках, которые от подножья охарактеризованного крупного обнажения напротив хутора Лееи прослеживаются вниз по р. Абава по обоим берегам. На левом берегу под бывшим хутором Муйжараи в косослоистых песчаниках вместе с глинистой и кварцевой галькой найдены обломки панцирей Watsonosteus sp. и Asterolepis ex. gr. ornata (на рис. 3 эти находки показаны на уровне ложи р. Абава).

Новые данные подтверждают вывод о продолжительности этапа развития бассейна со смешанной средне-позднедевонской ихтиофауной и правомерности выделения стратиграфического подразделения, названного П. П. Лиепиньшем абавской свитой. Однако ныне это подразделение не входит в состав живетского яруса, как это было принято ранее (Лиепиньш, 1960), а занимает основание разреза франского яруса, т. е. основание гауйской свиты, не имея при этом ранга самостоятельной свиты (Сорокин и др., 1981). Кстати, наличие «переходных слоев» со средне-позднедевонской ихтиофауной было установлено впервые В. Гроссом в бассейне р. Гауя и в Западной Латвии около населенного пункта Дундага (Gross, 1942), а также B. Н. КаратаютеґТалимаа в скв. Кряканава (Нарбутас, 1964) на территории центральной части Литвы.

Фауна рыб абавской свиты представлена видами, найденными из более древних отложений и отчасти переходящими в более молодые, т. е. 
В типичные гауйские, например, Ganosteus stellatus (найден в обнажениях Әрглю клинтис и Әрманю иезис). Весьма характерны рыбы, появляющиеся в данном подразделении: Psammolepis abavica, Watsonosteus sp., Livosteus grandis и Plourdosteus(?) panderi. Определения среднедевонского рода Homostius из того же ихтиокомплекса оказались впоследствии ошибочными. Однако, крупные представители рода Asterolepis - A. ornata Eichw. или же близкий к ним по размерам и строению, но более ранний $A$. essica Lyarskaya, сближают ихтиофауну абавской свиты с фауной гауйской свиты. A. essica описан из примерных возрастных аналогов абавской свиты в Эстонии (р. Выханду, местонахождения Эсси и Ратта мююр), где встречается вместе с Psammolepis abavica, Watsonosteus sp. и Microbrachius sp. Следует подчеркнуть, что представители родов Watsonosteus и Microbrachius в Шотландии известны из верхней части живетского яруса (Сорокин и др. 1981, табл. 8). Не исключено, что в абавской свите в дальнейшем можно выделить два подразделения, из которых нижний охарактеризован родом Watsonosteus, а верхний - родом Livosteus.

Выделение и прослеживание абавской свиты (и ее возрастных аналогов) представляет большой интерес, особенно в связи с детальным картированием переходных слоев среднего и верхнего девона на территории ряда районов Латвии, где они изучаются в целях поиска и прогноза новых месторождений полезных ископаемых. При этом трудноосуществимым остается прослеживание верхней границы абавской свиты, пересекающей, вероятно, разные по возрасту, но лишенные индивидуальных особенностей, слои гауйского горизонта. Достоверные материалы о распределении остатков средне-позднедевонских рыб могут быть получены, как известно, только при изучении обнажений, а керновый материал скважин для этого малопригоден. Наиболее благоприятные предпосылки для картирования абавской свиты имеются в бассейне р. Гауя и в Южной Эстонии, где много выходов на гюверхность пограничных слоев среднего и верхнего девона,

\section{ЛИТЕ Р А Т Р Р}

Куршс В. М. Ряды фациальных типов осадков и условня захоронения рыб в раннесреднедевонских бассейнах Латвии // Бнофации и фауна силурийского и девонских бассейнов Прибалтики. Рига, 1986, 61-72.

Лиепиньщ П. П. Девонская система // Геология СССР. Т. 38. Латвийская ССР. М., $1960,61-86$.

Лярская Л. А. К вопросу о границе между средним и верхним девоном в Латвии // Палеонтология и стратиграфия Прибалтики и Белоруссии. Вильнюс, 1966, 281286.

Нарбутас В. В. Стратиграфня и литология раннефранских отложений Польско-Литовской синеклизы в свете фациальной зональности франского бассейна на северозападе Русской платформы // Вопросы стратиграфии и палеогеографии девона Прибалтики. Вильнюс, $1964,89-104$.

Сорокин В. С., Лярская Л. А., Савваитова Л. М. и др. Девон и карбон Прибалтики. Рнга, 1981.

Gross, W. Die Fischfaunen des baltischen Devons und ihre biostratigraphische Bedeutung // Korrespondenzbl. Naturf.-Ver. Riga, 1942, 64, 373-436.

\footnotetext{
Ннститут геологии

Академии наук Эстонской ССР

Отдел геологии Латвийского

государственного университета
}

Поступнла в редакцию 9/I 1989 


\section{KESK- JA OLEMDEVONI PIIR ABAVA JŌE SUUDME PIIRKONNAS (LÄTIS)}

Mõnede paljandite ja puursüdamike uurimine lähiminevikus on näidanud, et Abava jõe alamjooksul eksisteerib tõepoolest stratigraafiline üksus, mida P. Liepiñ š nimetas omal ajal (1960) Abava kihistuks. Mainitud kihistust on leitud nii sellele ainuomaseid kalu kui ka lamavatest kihtidest tuntud vorme. Ohtlasi leidub Abava kihistus perekond Asterolepis'e suuri esindajaid ( $A$. ex gr. ornata, $A$. essica), mis on iseloomulikud Frasne'i ajajärgule. Abava kihistu vanuselisi analooge on teada ka Kagu-Eestist Võhandu jõelt.

\section{Elga KURIK, V. KURSS, Lyubov LYARSKAYA}

\section{THE MIDDLE AND UPPER DEVONIAN BOUNDARY IN THE ABAVA RIVER MOUTH REGION (LATVIA)}

The exposures on the lower reaches of the Abava River (e. g. Lejejji, Muizărāji) and the cores of the borings from the same region of western Latvia have been studied recently. The study confirms the view of P. Liepinš (Лиепиньш, 1960) that there exists a stratigraphic unit at the boundary of the Middle and Upper Devonian which he calls the Abava Formation. This formation contains its own specific representatives of the fish fauna (Psammolepis abavica, Watsonosteus sp., Livosteus grandis, Plourdosteus(?) panderi), some earlier forms (Ganosteus stellatus, Actinolepis) and characteristic Frasnian species, i.e. large asterolepids from the $A$. ornata group. In the Võhandu River outcrops (SE Estonia), in the probable age equivalent to the Abava Formation, such an Asterolepis species (A. essica) occurs together with $P$. abavica, Watsonosteus sp. and Microbrachius sp. The last two forms are known, however, from the Givetian of Scotland (see Сорокин и др., 1981, табл. 8). It is not excluded that the formation can be subdivided into two parts, the lower part being characterized by Watsonosteus and the upper one by Livosteus. 